\title{
Política, felicidad y ascetismo en el Régimen del solitario del filósofo zaragozano Ibn Bājja ${ }^{1}$
}

\author{
Luis Xavier López-Farjeat \\ Facultad de Filosofía \\ Universidad Panamericana \\ llopez@up.edu.mx
}

La recepción árabe de la filosofía griega es un tópico característico del mundo medieval. Abundan los comentarios árabes a los tratados filosóficos más representativos del pensamiento helénico. El contacto con esa clase de obras permitió que se generara la filosofía en el entorno árabe-islámico. Ésta, en general, estuvo marcada por las ideas de los dos filósofos mayores: Platón y Aristóteles. El primer comentador árabe de Aristóteles en Occidente fue el neoplatónico Ibn Bājja. Abū Bakr Muhammad ibn Yahyà ibn al-Sā'igh ibn Bājja, músico, poeta, médico y filósofo, nació en Zaragoza alrededor de 1080 y murió en Fez en el año 1138, envenenado por sus enemigos políticos con una berenjena. Avempace, como se le llamó en el mundo latino, conocía extraordinariamente bien el pensamiento de los filósofos árabes orientales y, en especial, el de al-Fārābī, el fundador de la filosofía política islámica. El proyecto político de Avempace se presenta en su obra titulada El régimen del solitario (Tadbìr al-mutawahhid)². Encontramos ahí distintas ideas platónico-

${ }^{1}$ Este trabajo forma parte de un proyecto de investigación dedicado a la filosofía de la mente y la filosofía de la acción en el aristotelismo árabe y latino, apoyado por CONACYT J49596-H. Agradezco a los miembros del equipo de investigación con quienes he tenido la oportunidad de discutir el tema.

2 Utilizaré la versión castellana de J. Lomba (1997). El profesor Lomba ha recurrido al manuscrito de la Biblioteca Bodleiana de Oxford (Pococke 206). Su traducción es de las mejores que se han hecho ya que cuenta con un buen aparato crítico y, además, coteja su propia traducción así como partes difícilmente legibles del manuscrito original con las traducciones que han hecho académicos como Asín Palacios, Dunlop, Fakhry, Ziyāda y, por supuesto con 
aristotélicas, farabianas, sufíes y, por supuesto, islámicas. La tesis central del Tadbīr es la siguiente: toda ciudad y sociedad es imperfecta; por lo tanto, la única felicidad posible será la del hombre aislado, ya sea él solo o en una comunidad:

[...] el régimen correcto únicamente será el del [hombre] aislado, tanto si se trata de uno solo como si son más, en tanto no se una la comunidad o la ciudad a sus doctrinas. A estos [solitarios] es los que los sufíes designan con el nombre de extranjeros, ya que, aunque vivan en sus propios países o entre sus compañeros y vecinos, [en realidad] son extranjeros en sus ideas, pues se han marchado con sus pensamientos a otros niveles [de vida] que son para ellos como sus patrias. Todo esto aparte de otras cosas que dicen $(1997 ; 102-3)$.

Avempace explicará, entonces, cómo debe regirse la vida del solitario para alcanzar la máxima perfección de su existencia. La tesis resulta desconcertante considerando que la vida política de un individuo supone la convivencia con la comunidad. Se vuelve todavía más desconcertante cuando descubrimos que el Tadbīr, un libro teóricamente de filosofía política, ofrece una alternativa para el individuo que, convencido de que no existe ninguna sociedad ni modelo político que resulte satisfactorio, decide alcanzar la felicidad por sus propios medios y en soledad o en una especie de comunidad aislada. Sin embargo, es sumamente coherente si tenemos en cuenta que muchas sociedades suponen un impedimento para la vida virtuosa. El objetivo de mi trabajo es discutir a la luz del Tadbìr de Avempace, si el fin último de la vida humana, es decir, la felicidad, se alcanza en las sociedades imperfectas o es preferible la vida en soledad del sabio asceta. Enunciado en otros términos, el problema del que me ocuparé es si la felicidad se alcanza dentro de una comunidad imperfecta o de manera solitaria.

la clásica traducción hebrea de Munk. 
La comunidad o umma islámica está unida fundamentalmente por la religión. En este sentido, no habría razones para pensar en la figura de un individuo místico o asceta retirado de la sociedad para alcanzar la felicidad por sí mismo. Tal como sucede en el modelo helénico, los individuos no pueden ser plenos al margen de la polis. Acaso por ello el interés de un personaje tan importante como alFārābī, es presentarnos un modelo político ideal, el que se aplicaría en la ciudad perfecta (madìna fādila) ${ }^{3}$. Al mismo tiempo, es el propio al-Fārābī quien afirma que le está prohibido al virtuoso vivir en una ciudad regida por políticas inmorales. El virtuoso debe emigrar siempre a ciudades virtuosas y, dice al-Fārābī, «si no existieran, el virtuoso será entonces un extraño en este mundo y su vida será un mal, y le será preferible antes morir que seguir viviendo» (1992; Fusūl 93). Una idea muy similar aparece en el Tadbìr de Avempace: el contraste entre la ciudad ideal y las ciudades existentes. Ante la inexistencia de la ciudad ideal aparece una opción más afortunada y conveniente para el virtuoso: si después de su nomadismo en busca de ciudades perfectas los resultados han sido estériles, es preferible que se refugie en sí mismo.

Al-Fārābī, como tiempo después, Avempace, considera que la ciudad ideal es el sitio adecuado para que los individuos sean felices. No obstante en los dos filósofos aparece un problema elemental: la inexistencia de una comunidad o una ciudad absolutamente virtuosa. De este modo, podemos descubrir que las ciudades exis-

${ }^{3}$ En el capítulo veintiséis de La ciudad ideal (Al-madīnat al-fādila), podemos leer: «El hombre es de tal condición y naturaleza que, para subsistir y alcanzar su más alta perfección, tienen necesidad de tantísimas cosas que es imposible que viviendo uno aisladamente se ocupe de todas; al contrario, necesita de compañeros, cada uno de los cuales se ocupe de algo que los otros necesitan. [...] Se asocian, pues, para así poder encontrar en la labor de todos lo que necesitan para que cada uno subsista y obtenga la perfección. [...] De este modo se han formado diversas sociedades humanas: perfectas unas y otras imperfectas». (1985; cap. XXVI, 82-3). No obstante, seguirá explicando al-Fārābī, la más perfecta de todas las sociedades se denominará Ciudad Modelo o Ciudad virtuosa y será aquella en la que «todos se ayuden mutuamente para obtener la felicidad» (1985; cap. XXVI, 83). El problema será si es posible encontrar una ciudad así. 
tentes no se ajustan a la ciudad ideal. A los dos filósofos les importa analizar la política de su tiempo y distinguir regímenes perfectos e imperfectos. El Tadbìr comienza con una disquisición sobre los sentidos del término 'régimen' (tadbīr) en la lengua árabe. Concluye Avempace que (a) el término debe aplicarse solamente al orden que pueden establecer seres dotados de razón y que, por lo tanto, pueden gobernar sus actos; (b) el régimen más excelente es el de Dios porque Él establece y gobierna el orden del mundo; (c) algo parecido sucede en el caso de los seres humanos: la ciudad requiere a un gobernante que guíe y ordene a los ciudadanos hacia el fin supremo, a saber, la felicidad.

El gobierno de los seres humanos es una copia imperfecta del gobierno divino. Por ello, es todavía más claro que no existe la ciudad perfecta. Ésta sería solamente un ideal que, paradójicamente, no se consigue a través de la organización política sino sólo de manera interior. Los gobiernos son incapaces de garantizar la libertad y felicidad de los ciudadanos y, por ello, la mejor alternativa no es el gobierno sino el autogobierno. Antes de revisar en qué consiste este autogobierno, Avempace critica las formas de gobierno imperfectas. Éstas son las mismas que aparecen en la República de Platón y en el Libro de la Política (Kitāb al- Siyāsa al-Madaniyya) ${ }^{4}$ de al-Fārābī: la timocracia, la oligarquía, la democracia y la tiranía. Escribe Avempace:

Algunos se han encargado de tratar el régimen de estas ciudades imperfectas, es decir, enfermas. Aquellos cuyos libros sobre el régimen de las casas nos han llegado hablan retóricamente para demostrar cuanto

${ }^{4}$ Frente a estos regímenes corruptos, en este Kitāb al-Siyāsa al-Madaniyya, al-Fārābī se refiere a una alternativa muy similar a la de Avempace: «El que es gobernante primero de manera absoluta no necesita para nada de hombre alguno que le gobierne, sino que a él ya se le han realizado en acto las ciencias y los conocimientos y no tiene necesidad de ningún hombre que lo guíe en algo, pues dispone de una excelente percepción de cada una de las cosas particulares que debe hacer; también es capaz de guiar excelentemente a todos los otros hacia todo aquello que les enseña, es capaz de utilizar a todo aquel que realiza alguna de las acciones para las que está preparado, y es capaz de determinar, definir y dirigir esas acciones hacia la felicidad» (1992; III, 1). Este personaje al que se refiere al-Fārāb̄̄ tendrá la capacidad de ser un verdadero rey y fundar una nación virtuosa, es decir, aquella que está constituida por hombres virtuosos, buenos y felices. 
hemos dicho, a saber: que las casas, exceptuando la casa perfecta, son enfermas; que todas ellas están pervertidas y que su existencia no es natural sino artificial [y por institución humana], razón por la cual sus virtudes [son también] sólo convencionales, salvo, claro está, en aquellas [cosas] en que coinciden con la casa perfecta, cuyo estudio tiene un orden conocido y necesario $(1997 ; 97)$.

En contraste con los regímenes enfermos, Avempace presenta una serie de consideraciones que recuerdan un pasaje de Platón. En concreto, República 405 a-c en donde se explica que en las ciudades viciosas se requiere un mayor número de jueces y médicos porque ahí se cometen más injusticias y los ciudadanos son intemperantes. En este pasaje del Tadbīr se destaca la importancia de virtudes fundamentales dentro de la ciudad perfecta, a saber, la amistad y la justicia:

La ciudad perfecta se caracteriza porque en ella está ausente el arte de la medicina y el de la jurisprudencia y eso porque el amor une mutuamente [a sus habitantes los cuales, en consecuencia] no discuten entre sí en absoluto. Por eso, si falta el amor en uno de los miembros [de esa ciudad] y sobreviene la discordia, es preciso, entonces, que se restablezca la justicia y, por tanto, se necesitará inexorablemente de alguien que la cumpla, a saber: del juez (1997; 98-9).

Los habitantes de la ciudad perfecta no necesitan de la medicina porque no ingieren alimentos nocivos, no abusan del vino $\mathrm{y}$ tampoco dejan de practicar el ejercicio. Por otra parte, tampoco necesitan de un juez porque los habitantes son justos y las opiniones de todos son verdaderas: no hay falsedad, no existe la mentira. Escribe Avempace:

Es evidente que en la ciudad perfecta y completa a cada uno se le da aquello que más le conviene, que todas las opiniones [que hay] en ella son verdaderas y ninguna falsa, que las acciones que se realizan son absoluta y exclusivamente virtuosas y que todas las obras que se dan fuera [de la ciudad perfecta], aunque sean buenas, lo serán con relación a algún mal existente [en ella] (1997; 99).

Avempace considera que toda opinión emitida por cualquiera que no habite en la ciudad perfecta, será falsa; de la misma mane- 
ra, sus acciones serán erradas. Con afirmaciones tan terminantes lo que Avempace quiere decir es que solamente los habitantes de la ciudad perfecta se guían por la demostración y la virtud, mientras que los habitantes de las ciudades imperfectas se guían por la opinión y en muchas ocasiones ésta conduce a la maldad y la ignorancia. Existen varias dificultades en las ciudades imperfectas en las que se gobierna conforme a la opinión: en efecto, se pueden tener en cuenta opiniones equivocadas o puede darse que alguien dé con algo verdadero y, por ser distinto a lo que se profesa en la ciudad, se le considera un brote (nābit). El término árabe nābit significa, en efecto, 'brotar', 'crecer', 'germinar'. Avempace escribe: «[...] los que caen en la cuenta de una doctrina verdadera que no existía antes en aquella ciudad o que es contraria a las profesadas en ella, estos tales ciertamente reciben el nombre de «brotes» (nawābit)» (1997; 101). La aparición de un 'brote' admite un sentido despectivo, es decir, podría referirse el brote al crecimiento de hierba mala o de la cizaña (cf. 1997; 101, n. 39). Avempace la da un sentido positivo consiguiendo con ello una buena metáfora: los virtuosos, los que descubren la verdad de un doctrina, se vuelven el brote, son la hierba que hace falta separar [ «Este nombre se les atribuye por traslación de las hierbas que brotan espontáneamente de los sembrados. Nosotros, por nuestra parte, usamos específicamente este nombre para quienes piensan ideas verdaderas» $(1997 ; 101)]$.

En las ciudades imperfectas encontraremos tres clases de personas que son inexistentes en la ciudad perfecta: jueces, médicos y brotes. Lo interesante es que los brotes podrían ser la causa de que se dé la ciudad perfecta (cf. 1997; 102). Dado que existen solamente ciudades imperfectas, los virtuosos comprenden que solamente alcanzarán la felicidad aislándose, separándose del resto de la cosecha. Ahora bien, ¿cómo es posible que el virtuoso alcance la felicidad y la máxima perfección viviendo de manera no natural, es decir, negando su naturaleza social? Cabe también una contra-pregunta, ¿por qué tendríamos que creer que la felicidad se alcanza solamente en la ciudad si los regímenes serán siempre imperfectos? 
Para Avempace es capital el tema de la felicidad. Dos de sus obras, Carta sobre el fin último del hombre (Risāla fì-l-gāyat al-insān $)^{5}$ y la Carta del adiós (Risāla al-wadā $)^{6}$, insisten en que el fin primordial de la vida humana es la felicidad y ésta se consigue optando por la sabiduría. En el Tadbīr, el trabajo que nos ocupa, Avempace propone, como ya he dicho, que el mejor modo de vida consiste en la soledad y la reflexión. Dado que todas las sociedades y toda práctica política son corruptas, la alternativa más afortunada es la vida reflexiva en soledad. Ésta es la única manera de que el ser humano alcance su fin último. La vida reflexiva no es sino el cultivo de la sabiduría hasta alcanzar la unidad con el intelecto agente (cf. 2002; 33-48).

En efecto, la felicidad se alcanza en la unidad con el intelecto agente y, por ello, el Tadbīr, como toda la filosofía de Avempace, da a su pensamiento político un soporte metafísico y también epistemológico. Avempace presenta una especie de experiencia mística intelectual que consiste en la unión con el intelecto agente, el pensamiento puro y lo que denomina 'formas inteligibles sin materia'. En esta experiencia radica la felicidad. Así las cosas, la felicidad última del ser humano consistiría en la unión absoluta del almaintelecto del individuo y el intelecto agente. No obstante, dicha unión con el intelecto llevaría consigo la disolución del individuo.

5 En este escrito Avempace afirma que «El fin humano es uno solo, el cual es el principal, estando cada uno de los otros fines, sean cuales sean, subordinados a éste. El hombre señor por naturaleza es el que se prepara para este fin. Y quien no se prepara para este fin, está por naturaleza gobernado. Por eso hay gentes que están por naturaleza gobernadas y las hay que tienen el señorío por naturaleza. Unos dominan a los demás y otros son dominados por otros. Se demostró en muchos lugares que aquel fin es eterno, que no es generable ni corruptible y que es o los inteligibles o uno de ellos» (1993-1994; 474).

${ }^{6}$ Resulta sumamente ilustrativo el modo en que Avempace se refiere al fin absoluto de la vida humana en esta Carta del adiós: «Has de saber además - dice- que el hombre que llega a alcanzar ese [último] grado, se encuentra ya en un estado en el que ni la naturaleza física le combate ni el alma bestial le mueve a guerra. Mas el conocimiento de este estado en el cual logra la liberación de esos dos asaltantes, quiero decir de la naturaleza y del alma bestial, es el conocimiento de un estado que no puede descubrirse más que diciendo lo que he dicho, pues es un estado inefable, que sobrepasa al humano lenguaje por su grandeza, su nobleza, su hermosura y aun por el deleite que produce» (1943; 29, 83; versión árabe; 38). 
Nos encontramos aquí con un problema que provocó distintas condenas hacia el pensamiento de Avempace, especialmente por parte de pensadores cristianos como Alberto Magno (cf. 2005; 171-210) y Tomás de Aquino (cf. 2004; 95-107): ¿cómo es posible que el alma humana personal se disuelva al unirse con el intelecto agente, único y universal, totalmente separado, inmortal y eterno? ¿Cómo elaborar una doctrina del intelecto compatible con la individualidad del alma humana? Por último, ¿qué sentido tendría la felicidad si su alcance supone la disolución radical del yo-individuo?

Se discute si la disolución absoluta del individuo hay que leerla literal o alegóricamente. Parecería que la lectura de los críticos de Avempace es excesivamente literal. J. Lomba, uno de los pocos especialistas en la filosofía del zaragozano, ha sugerido la posibilidad de que la unión con el intelecto agente no sea sino una alegoría, una afirmación con sentido esotérico (cf. 2001; 136). Podría ser, en efecto, que Avempace se estuviera refiriendo en sentido figurado a la necesidad del solitario de separarse de las comunidades imperfectas para unirse con los de su clase, solitarios unidos por el amor a la verdad y la vida buena. Propongo seguir esta misma línea de la lectura alegórica. Ello nos permite elaborar una interpretación mucho más flexible de la filosofía de Avempace en la que lo que se propone es el abandono metafórico de las sociedades imperfectas para que el individuo se concentre en su interior. Este 'interiorismo', tal como sucede con san Agustín, es la vía más certera para la felicidad y la identificación de lo más divino. Lo que haré a continuación es, precisamente, presentar esa interpretación de Avempace que he denominado flexible.

Mencionaba líneas arriba ese pasaje en el que al-Fārābī menciona que para un virtuoso sería preferible la muerte que una ciudad inmoral. Avempace propone una salida menos radical. Ya la conocemos: el aislamiento. El solitario no es un activista político ni un juez o inquisidor de las ciudades imperfectas. No le interesa, siquiera, organizar alguna revuelta para enderezar el rumbo de las ciudades o mejorar los regímenes. Su mirada está puesta en algo mucho más noble y elevado.

Escribe Avempace: 
¿Convendría al solitario convertirse en juez de aquellos en medio de los cuales habita? Mejor, en verdad, será que se consagre a sus ejercicios del culto divino y que eche lejos de sí tan pesada carga, perfeccionándose a sí mismo y brillando para los demás como una luz. En secreto es como debe entregarse al culto del Creador, como si esto fuese una cosa vergonzosa, y aquí se perfeccionará tanto en su ciencia como en su religión y agradará a Dios, debiendo huir a aquellas sociedades en que haya ciencias, si es que las hay, y relacionarse con los hombres de edad madura que se distingan por su buen juicio, su ciencia, su inteligencia y en general por sus virtudes intelectuales, como hombres ya formados, no como jóvenes inexpertos $(1997 ; 168)$.

El solitario cultiva una única ciencia, la teórica, y deja atrás esas 'ciencias' a las que refiere el pasaje que son, como dijimos, la medicina y la jurisprudencia. Su ciencia es la sabiduría y ésta la cultivan solamente los hombres maduros, los ancianos. De éstos afirma Avempace que ellos deberán «[...] de tener únicamente sabiduría, puesto que es lo que más cuadra. Ésta es la razón de que ponga Sócrates a los hombres que tienen tal edad, cuando son sabios, en las islas de los Afortunados» $(1997 ; 145)^{7}$. Pero, ¿no es esta iniciativa del

7 Y, en efecto, en la República hay varios pasajes en los que se discute si lo propio del filósofo es aislarse o participar activamente en la vida política. La respuesta no es sencilla: si bien los diálogos apuntan a que es necesario apoyarse en los sabios para mejorar la vida de la ciudad, también se alude a que solicitarle a estos personajes que participen, podría ser una injusticia. Recordemos uno de estos pasajes: «Por cierto, es una tarea de nosotros los fundadores de este Estado, la de obligar a los hombres de naturaleza mejor dotada a emprender el estudio que hemos dicho antes que era el supremo, contemplar el Bien y llevar a cabo aquel ascenso y, tras haber ascendido y contemplado suficientemente, no permitirles lo que ahora se les permite» (519 c-d) [se refiere a «Quedarse allí y no estar dispuestos a descender junto a aquellos prisioneros, ni participar en sus trabajos y recompensas, sean éstas insignificantes o valiosas» (519 d)]. Y más adelante, en 519 e - 520 a-c, se discute si no se estará cometiendo una injusticia con los filósofos al hacerlos participar en algo tan mundano. Se insiste en otras partes en que no hay nada sano en la política y es más conveniente que el filósofo se aísle. Por ejemplo: «Quedan entonces, Adimanto, muy pocos que puedan tratar con la filosofía de manera digna: alguno fogueado en el exilio, de carácter noble y bien educado, que, a falta de quienes le perviertan, permanece en la filosofía; o bien un alma grande que nace en un Estado pequeño y desprecia, teniéndolos en menos, los asuntos políticos; o bien algunos pocos dotados naturalmente que con justicia desdeñan los demás y se acercan a la filosofía. [...] Y los que han sido de estos pocos que hemos enumerado y han gustado el regocijo y la felicidad de tal posesión, pueden percibir suficientemente la locura de la muchedumbre, así 
aislamiento, como ya decía líneas arriba, una actitud contra natura, si es que es verdaderamente cierta la tesis aristotélica del hayawān madañ o animal político? ¿No supone al menos una contradicción con lo dicho en la Política de Aristóteles? Avempace responde:

Esto no está en contradicción con lo que se dijo en la ciencia política, ni con lo que se demostró en la ciencia natural. Allí, en efecto, se hizo evidente que el hombre es social por naturaleza y en la ciencia política quedó patente que todo aislamiento es malo. Sin embargo, esto es así únicamente por esencia, pero accidentalmente [el aislarse puede] ser bueno, como ocurre en muchas cosas que se dan en la naturaleza. Por ejemplo: el pan y la carne son cosas que la naturaleza alimentan y son útiles, mientras que el opio y la coloquíntida son venenos mortales. Sin embargo, se dan a veces en el cuerpo estados no naturales, en los cuales ambas cosas [es decir, el opio y la coloquíntida] benefician y se deben emplear, mientras que los alimentos naturales [que hemos dicho] perjudican, siendo necesario evitarlos. No obstante, estas situaciones constituyen forzosamente enfermedades que están al margen de la naturaleza, siendo [los venenos] útiles en pocas ocasiones y por accidente, mientras que los alimentos son beneficiosos en la mayoría de las veces y de modo esencial.

Así pues, la relación de aquellas situaciones [de los venenos y alimentos] guardan con los cuerpos es la misma que existe entre los modos de vida [social] y el alma. Del mismo modo que se piensa que la salud es una, en contraposición con [las enfermedades] que son muchas, y que sólo la salud es lo natural para el cuerpo, mientras que las múltiples [enfermedades] son extrañas a la naturaleza, así también la sociedad perfecta es lo único que es natural al alma, siendo contraria a las demás sociedades las cuales son múltiples, y lo múltiple es ajeno al alma $(1997 ; 168-9)$.

El aislamiento es benéfico, pues, por accidente. Pero no se trata de un aislamiento absoluto, no se trata de un retiro total del mun-

como que no hay nada sano - por así decirlo - en la actividad política, y que no cuentan con ningún aliado con el cual puedan acudir en socorro de las causas justas y conservar la vida, sino que, como un hombre que ha caído entre fieras, no están dispuestos a uníseles en el daño ni son capaces de hacer frente a su furia salvaje, y que, antes de prestar algún servicio al Estado o a los amigos, han de perecer sin resultar de provecho para sí mismo o para los demás» (496 b-d). 
do. Leíamos en el pasaje que cité al inicio que aunque los solitarios «vivan en sus propios países o entre sus compañeros y vecinos, [en realidad] son extranjeros en sus ideas, pues se han marchado con sus pensamientos a otros niveles [de vida] que son para ellos como sus patrias» (1997; 103). El solitario se conoce a sí mismo y se autogobierna, se ocupa de su interior; su ascetismo le ayuda a no ser víctima de los placeres, las pasiones y cualquier tipo de experiencia primaria de las que ofrece lo mundano; cultiva la sabiduría para sí mismo y en su intimidad logra percatarse de que la verdadera felicidad radica en una unión místico-intelectual con el Ser Supremo. Este sosiego intelectual y ese escenario para la reflexión y la vida virtuosa, es lo que los Reinos de Taifas de al-Andalus y los almorávides de su tiempo, no lograron darle al filósofo Avempace. Todo lo contrario: los almorávides lo encarcelaron dos ocasiones y sus enemigos políticos lo asesinaron.

\section{III}

El solitario de Avempace no es un eremita ni un anacoreta. Su aislamiento es una alegoría: se retira de las ciudades imperfectas para ocuparse de su interioridad. Las sociedades enfermas de aquellas ciudades se han habituado a las falsas opiniones y creencias: el virtuoso no se dejará alienar, no se dejará contagiar por una sociedad enferma y, por ello, externamente parecerá que vive como los demás miembros de la comunidad pero, en realidad, se ha marchado hacia él mismo.

La capacidad reflexiva del solitario le permite percatarse de que la única manera de ser feliz es violentar su sociabilidad natural:

Por tanto resulta claro que el solitario, dada su índole, no debe acompañarse de los hombres materiales ni de los que tienen un fin espiritual mezclado con materialidad ni aun de los que no tienen por fin lo espiritual absoluto, sino que están en la obligación de rodearse de la gente de ciencia. Pero como los hombres de ciencia escasean en algunas formas de vida social mientras que son abundantes en otras e incluso llegan a faltar por completo en algunas, por esa razón, el solitario está obligado en algunas sociedades a apartarse por completo 
de la gente, en cuanto le sea posible, y no mezclarse con ellos sino en las cosas necesarias o en la medida en que le es indispensable. Debe el solitario alejarlos de sí, porque no son de su especie; no se mezclará con ellos, ni dará oído a su charlatanería, para no tener necesidad de deshacer sus mentiras, perseguir con odio a los enemigos de Dios y perseguir su juicio adverso contra ellos $(1997 ; 168)$.

El solitario enfrentará una paradoja: por una parte, sabe que todo ser humano necesita de la sociedad y, por ello, externamente cumple sus obligaciones sociales con disimulo, como si fuese un ciudadano más; por otra, sabe que debe salvar su libertad y felicidad y, para ello, interiormente prescinde por completo de la comunidad. Y es que, en efecto, al sabio la sociedad le es hostil y adversa; insisto, puede ser un impedimento para la virtud. Por ello, siempre será un brote, no se someterá a las leyes y convenciones que rigen a los seres humanos comunes y corrientes. Pero no se trata de remar contracorriente, sino de optar por una vida alterna dedicada al cultivo de las virtudes morales e intelectuales. Se trata, en algún sentido, de un ascetismo que paulatinamente le conduce a una visión místico-intelectual de Dios.

En las primeras líneas advertía que me ocuparía de la siguiente cuestión: dado que no existe la ciudad perfecta, ¿será verdad que es mejor para el virtuoso, aislarse que soportar los regímenes imperfectos de las ciudades existentes? Me inclino a pensar que Avempace tiene razón en parte de su planteamiento: así como el brote del virtuoso podría ser el inicio de la ciudad perfecta, el autogobierno también es un rasgo indispensable para que exista un buen gobierno. Los regímenes imperfectos tratan de regular la vida de ciudadanos no virtuosos, de individuos que no se autogobiernan y esperan que un Estado o la mayoría sean quienes establezcan los mecanismos cívicos y morales como si éstos se impusieran desde el exterior. Avempace apela en su planteamiento al interior asemejándose en cierto sentido a la autonomía kantiana. Con ello nos sugiere que la vida virtuosa o moral brota del propio individuo y no es un conjunto de disposiciones dadas a él por agentes externos. En este sentido, la ciudad perfecta supone que sus habitantes, los solitarios, son capaces del autogobierno. No obstante, es un he- 
cho significativo que lo más común sea encontrarse con ciudades imperfectas. Por ello, el planteamiento de Avempace también nos enfrenta a una realidad antropológica: la imperfección de la condición humana. Al mismo tiempo, recuerda una problemática recurrente en la filosofía política moderna: la escisión que existe entre el individuo y la comunidad.

El régimen del solitario evoca, a mi parecer, uno de los pasajes más bellos de la filosofía. Aquel que aparece en la Apología de Sócrates cuando éste dice:

Quizá pueda parecer extraño que yo privadamente, yendo de una a otra parte, dé a esos consejos y me meta en muchas cosas, y no me atreva en público a subir a la tribuna del pueblo y dar consejos a la ciudad. La causa de esto es lo que vosotros me habéis oído decir muchas veces, en muchos lugares, a saber, que hay junto a mí algo divino y demoníaco; esto también lo incluye en la acusación Meleto burlándose. Está conmigo desde niño, toma forma de voz y, cuando se manifiesta, siempre me disuade de lo que voy a hacer, jamás me incita. Es esto lo que se opone a que yo ejerza la política, y me parece que se opone muy acertadamente. En efecto, sabed bien, atenienses, que si yo hubiera intentado anteriormente realizar actos políticos, habría muerto hace tiempo y no os habría sido útil a vosotros ni a mí mismo. Y no os irritéis conmigo porque digo la verdad. En efecto, no hay hombre que pueda conservar la vida, si se opone noblemente a vosotros o a cualquier otro pueblo y si trata de impedir que sucedan en la ciudad muchas cosas injustas e ilegales; por el contrario, es necesario que el que, en realidad lucha por la justicia, si pretende vivir un poco de tiempo, actúe privada y no públicamente (Rep. 31 d-32 a).

\section{Bibliografía}

AL-FĀRĀB̄̄. 1985. La ciudad ideal (Alonso De Manuel Trad.). Madrid: Tecnos.

AL-FĀRĀBī. 1992. Obras Filosófico-Políticas (Rafael Ramón Guerrero Trad.). Madrid: Debate-CSIC [incluye los Artículos de ciencia política (Fusūl al-Madañ̄), el Libro de la religión (Kitāb al-Milla) y el Libro de la política (Kitāb al-Siyāsa al-Madaniyya)].

Avempace. 1943. «Carta del adiós» (Asín Palacios Trad.), Al-Anda- 
lus 8: 1-87.

Avempace. 1993-1994. «Sobre el fin del hombre»(J. Lomba Trad.), Sarq al-Andalus 10-11: 467-82.

Avempace. 1997. El régimen del solitario (J. Lomba Trad.). Madrid: Trotta.

LoмвA, Joaquín. 2001. La idea de felicidad en el Aragón musulmán. Zaragoza: Universidad de Zaragoza.

Lомва, Joaquín. 2002. «El lugar del intelecto agente en el pensamiento de Avempace», Revista Española de Filosofía Medieval 9 (Sociedad de Filosofía Medieval): 33-48.

López-Farjeat, Luis Xavier. 2005. «Avempace en el De anima de Alberto Magno», Tópicos 29 (Universidad Panamericana): 171210.

Matula, J. 2004. «Thomas Aquinas and his criticism of Avempace's Theory of the Intellect», Verbum 17/I (Akadémiai Kjadó, Budapest): 95-107.

Platón. 2003. República (Conrado Eggers Trad.). Madrid: Gredos.

\section{RESUMEN}

El autor argumenta que Avempace, extraordinario conocedor de los filósofos árabes orientales y, en especial, el de al-Fārābī, en su obra titulada El régimen del solitario (Tadbìr al-mutawahhid) defiende que toda ciudad y sociedad es imperfecta; por lo tanto, la única felicidad posible será la del hombre aislado, ya sea él solo o en una comunidad. Concluye que el planteamiento de Avempace nos enfrenta a una realidad antropológica: la imperfección de la condición humana; al mismo tiempo que nos recuerda una problemática recurrente en la filosofía política moderna: la escisión que existe entre el individuo y la comunidad.

Palabras clave: Avempace; El régimen del solitario; individuo; comunidad; sociedad imperfecta. 


\section{ABSTRACT}

The author argues that Avempace, special expert on the Arab eastern philosophers, particularly that of al-Farabi, in his book entitled The Regime of the Solitary (Tadbir al-mutawahhid) argues that every city and society is imperfect and therefore the only possible happiness will be that of the man's isolated, either alone or in a community. It concludes that the approach of Avempace confronts us with an anthropological reality: the imperfection of the human condition; at the same time that reminds us of a recurring problem in modern political philosophy: the split between the individual and the community.

Key words: Avempace; The Regime of the Solitary; individual; community; imperfect society. 
